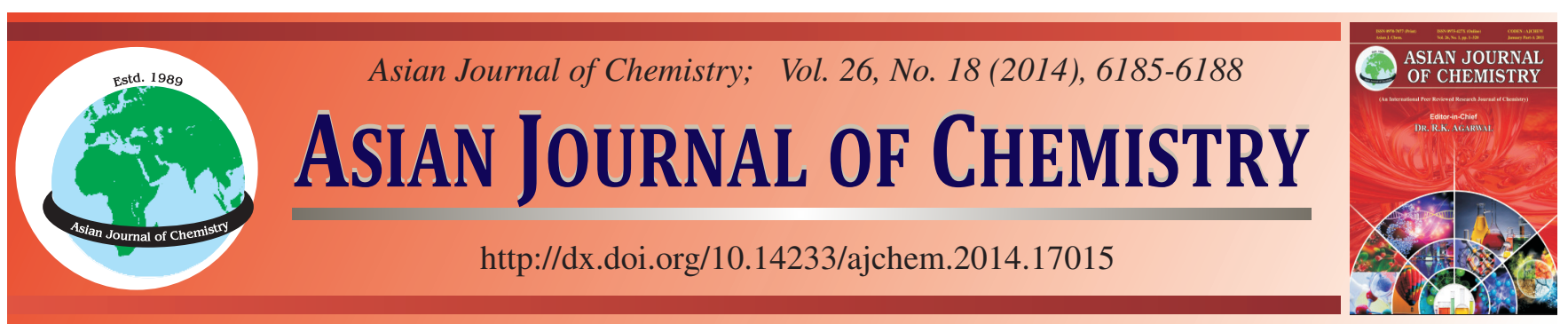

\title{
New Acyclic Triterpenoid Glycoside Constituent from the Fruits of Lycium chinense
}

\author{
Nasir A. Siddiqui ${ }^{1}$, Ill-Min Chung ${ }^{2}$, Praveen Nagella², Mohd Ali ${ }^{3}$, Perwez Alam¹ and Ateeque Ahmad ${ }^{2, *}$
}

${ }^{1}$ Department of Pharmacognosy, College of Pharmacy, King Saud University, Riyadh-11451, Kingdom of Saudi Arabia

${ }^{2}$ Department of Applied Bioscience, Konkuk University, Seoul 143-701, Republic of Korea

${ }^{3}$ Faculty of Pharmacy, Hamdard University, New Delhi-110062, India

*Corresponding author: E-mail: ateeque97@gmail.com

Received: 9 January 2014;

Accepted: 21 April 2014;

Published online: 1 September 2014;

AJC-15878

One new acyclic triterpenoid constituent as 14,18,22-trimethyl $3 \alpha, 5 \alpha, 17 \alpha, 19 \alpha, 22 \alpha$-pentahydroxytetracosan-25,26,27-trioic acid-3 $\alpha$ - $O$ $\alpha$-L-glucofuranosyl-(6a $\rightarrow 1$ 'a)- $O$ - $\alpha$-L-glucopyranosyl-(6'a $\rightarrow 1$ "a)- $O$ - $\alpha$-L-glucopyranoside- $5 \alpha-O$ - $\alpha$-L-glucofuranosyl-(6b $\rightarrow 1$ 'b)- $O$ - $\alpha$-Lglucopyranosyl-(6'b $\rightarrow 1$ "b)-glucopyranoside-17 $\alpha-O$-L-glucopyranosyl-(6c $\rightarrow 1$ 'c)- $O$-L-glucopyranosyl-(6'c $\rightarrow 1$ "c)- $O$-L-glucopyranoside$19 \alpha$ - $O$-L-glycopyranosyl-(6d $\rightarrow 1$ 'd)- $O$ - $\alpha$-L-glucopyranosyl-(6'd $\rightarrow 1$ "d)- $O$ - $\alpha$-L-glucopyranoside $(1)$ was isolated and identified from the fruits of Lycium chinense. The chemical structure of the new compound was elucidated by 1D and 2D NMR spectroscopic techniques (COSY, HMBC and HSQC) aided by FAB mass and IR spectra.

Keywords: Lycium chinense, Solanaceae, New constituent.

\section{INTRODUCTION}

Lycium chinense Miller fruits (Fructus Lycii; berries) known as Gou-Qi-Zi (Goji) in Chinese, have long history of application as a valuable tonic, juice and health food supplement for improving vision and maintaining good health in all aspects. It is reputed to have the properties of nourishing the blood, enriching the yin, tonifying the kidney and liver, moistening the lungs ${ }^{1,2}$. Fruits of $L$. chinense (Solanaceae), distributed in northeast Asia, specially in China, Japan, Korea and Taiwan, have been widely used as a food and tonic in traditional medicine. Two species of $L$. chinense and $L$. barbarum, which have been used for a long time as food and medicinal plants in China and other Asian countries ${ }^{3}$. Potential isolated constituents were reported to exhibit hypertensive, hypoglycemic and antipyretic activities ${ }^{4,5}$. Several compounds such as cerebrosides and lyciumamide in this plant are known to display various bioactivities ${ }^{6,7}$. Potentially hepatoprotective glycolipid constituents and determination of betain in $L$. chinense fruits have been reported ${ }^{8,9}$. Antimicrobial compounds were also reported from $L$. chinense roots ${ }^{10}$. Specific $\alpha$-galactosidase inhibitors, N-methylcalystegines structure/activity relationship of calystegines from $L$. chinense have been reported $^{11}$. The plant is reported to possess antibacterial, anticancer and antioxidant properties ${ }^{10,12,13}$. Antihepatotoxic activity and chemical constituents from $L$. chinense fruits have been reported ${ }^{6,14}$.
Several compounds such as cyclic peptides, acyclic diterpene glycosides and other compounds from L. chinense $e^{15}$, glycoconjugate from $L$. barbarum have been reported ${ }^{16}$. Variation in fruit sugar composition of $L$. barbarum and $L$. chinense of different regions and varieties were also reported ${ }^{17}$. Evaluation of antioxidant and other activities of compounds from $L$. barbarum and $L$. chinense have been reported ${ }^{18,19}$. Some glycosidic compounds and furalactone-type lignan were also recently reported ${ }^{20-22}$. Due to significance of fruits of this plant in medicinal use, the work in this area has already been done. In continuation of our study on Lycium fruits of $L$. chinense constituents, we have reported new and known compounds ${ }^{20,21}$. This aim of the present study was to isolate and characterize the one more new compound (Fig. 1) from the fruits of $L$. chinense.

\section{EXPERIMENTAL}

Melting points were determined using a model IA9100 melting point apparatus (Electrochemical Engineering, Seoul, South Korea). Optical rotations were measured with a model AA-10 polarimeter (Instrument Ltd., Seoul, South Korea). IR spectra were recorded on a Thermo-Scientific FT-IR model Nicolet 6700 (USA) spectrophotometer at the Korea Institute of Science and Technology, (KIST) Seoul, South Korea. ${ }^{1} \mathrm{H}$ and ${ }^{13} \mathrm{C}$ NMR spectra were obtained at 600 and $150 \mathrm{MHz}$, respectively, using a Bruker Avance-600 spectrometer, available at National Instrumentation Center for Environmental 


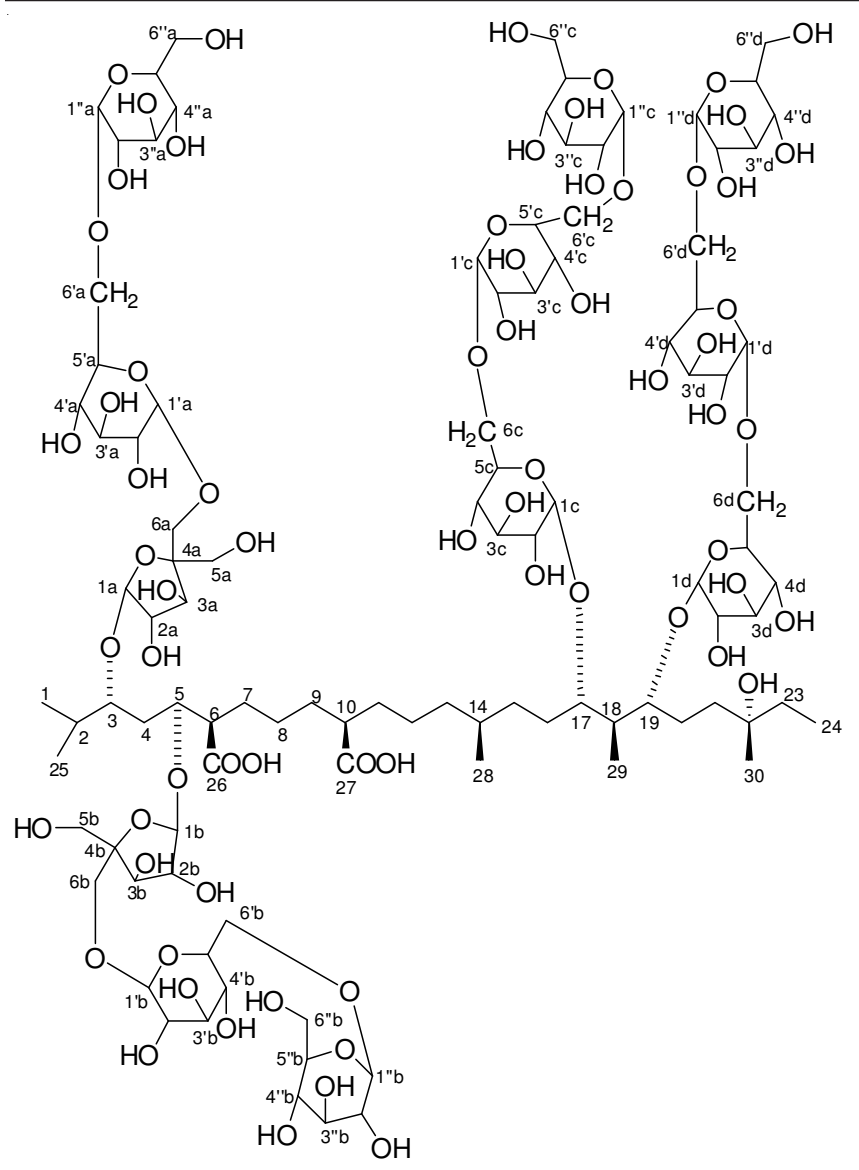

Fig. 1. Chemical structure of compound $\mathbf{1}$

Management (NICEM), College of Agriculture and Life Science, Seoul National University (SNU), Seoul, South Korea. NMR spectra were obtained in deuterated methanol using tetramethylsilane (TMS) as an internal standard, with chemical shifts expressed in parts per million $(\delta)$ and coupling constants $(J)$ in hetz. FAB MS data were recorded on a JMS-700 (Jeol, Japan) spectrometer instrument which was available at SNU, Seoul, South Korea. All chemicals were of analytical grade. $n$-Hexane, ethyl acetate, chloroform, methanol, ethanol, water, sulphuric acid and vanillin were purchased from Daejung Chemicals and Metals (Seoul, South Korea). Thin-layer chromatography was performed on pre-coated silica gel 60 F254 plates (Merck). Visualization of the TLC plates was performed using $5 \% \mathrm{H}_{2} \mathrm{SO}_{4}$ in ethanol spray reagent. Column chromatography was performed using silica gel (70-230 mesh) and LiChroprep RP-18 [40-63 $\mu \mathrm{m}$; octadecyl silica (ODS) gel] from Merck.

Fruits of $L$. chinense were purchased from local medicinal plant shops from the market in Seoul, Korea in September 2010 and were identified by the Head of Department of Pharmacognosy. Voucher specimen No. KU/LC/2010 has been deposited in Department of Applied Life Science, Konkuk University.

Extraction of fruits: Dried fruits of $L$. chinense $(3.1 \mathrm{~kg})$ were immersed in methanol (8 litres) for three days at room temperature and then the supernatant was concentrated under vacuum to yield $230 \mathrm{~g}$ of the extract, which was suspended in water and extracted with hexane, ethyl acetate and $n$-butanol successively to produce $20,10.1$ and 40 g extracts, respectively.
Isolation of the compounds from $\boldsymbol{n}$-butanol extract: The entire butanol extract was subjected to normal phase column chromatography over silica gel $(600 \mathrm{~g})$ to yield 28 fractions (each of $500 \mathrm{~mL}$ ) with the following eluants: fractions 1-2 with $\mathrm{CHCl}_{3}$, fractions 3-4 with $\mathrm{CHCl}_{3}-\mathrm{MeOH}$ (9.5:0.5, v/v), fractions 5-6 with $\mathrm{CHCl}_{3}-\mathrm{MeOH}(9: 1, \mathrm{v} / \mathrm{v})$, fractions 7-8 with $\mathrm{CHCl}_{3}-\mathrm{MeOH}(8: 2, \mathrm{v} / \mathrm{v})$, fractions 9-10 with $\mathrm{CHCl}_{3-}$ $\mathrm{MeOH}(7: 3, \mathrm{v} / \mathrm{v})$, fractions 11-12 with $\mathrm{CHCl}_{3}-\mathrm{MeOH}$ (6:4, v/v), fractions 13-14 with $\mathrm{CHCl}_{3}-\mathrm{MeOH}(1: 1, \mathrm{v} / \mathrm{v})$, fractions 15-16 with $\mathrm{CHCl}_{3}-\mathrm{MeOH}$ (4:6, v/v), fractions 17-18 with $\mathrm{CHCl}_{3}-\mathrm{MeOH}(3: 7, \mathrm{v} / \mathrm{v})$, fractions $19-20$ with $\mathrm{CHCl}_{3}-\mathrm{MeOH}$ (2:8, v/v), fractions 21-22 with $\mathrm{CHCl}_{3}-\mathrm{MeOH}(1: 9, \mathrm{v} / \mathrm{v})$ and fractions 23-28 with $\mathrm{MeOH}$. All fractions were examined by TLC. Fractions 1-4 were not further separated due to the low amount of the substance. Fractions 5-6 (0.9 g) were crystallized after the purification by column chromatography, yielding $\beta$ sitosterol-3-O- $\beta$-D-glucoside whose identity was confirmed through the comparison of TLC and spectroscopic data with those of an authentic sample. Fractions 7-8 (4.4 g) were re-chromatographed over LiChroprep RP-18 (ODS silica gel; 40-63 $\mu \mathrm{m}$ : $200 \mathrm{~g}$; each fraction $100 \mathrm{~mL}$ ). The elution was sequentially performed with methanol and water to yield 20 fractions. Fractions 1-4 with $\mathrm{H}_{2} \mathrm{O}-\mathrm{MeOH}(8: 2$, v/v), fractions 5-8 with $\mathrm{H}_{2} \mathrm{O}-\mathrm{MeOH}\left(6: 4\right.$, v/v), fractions 9-12 with $\mathrm{H}_{2} \mathrm{O}-$ $\mathrm{MeOH}(4: 6, v / v)$, fractions 13-16 with $\mathrm{H}_{2} \mathrm{O}-\mathrm{MeOH}(2: 8, \mathrm{v} / \mathrm{v})$, 17-20 with methanol. Fractions 13-16 after rechromatography over Lichroprep RP18 ODS (80 g, each fraction of $50 \mathrm{~mL}$ ). The elution was sequentially performed with methanol containing $80,60,40,20,10$ and $0 \%$ of water to yield one new compounds 1 .

$14,18,22$-trimethyl $3 \alpha, 5 \alpha, 17 \alpha, 19 \alpha, 22 \alpha$-pentahydroxytetracosan-25,26,27-trioic acid-3 $\alpha-O-\alpha$-L-glucofuranosyl$\left(6 \mathrm{a} \rightarrow 1^{\prime} \mathrm{a}\right)-O$ - $\alpha$-L-glucopyranosyl-(6'a $\left.\rightarrow 1^{\prime \prime} \mathrm{a}\right)-O-\alpha-\mathrm{L}-$ glucopyranoside-5 $\alpha-O$ - $\alpha$-L-glucofuranosyl-(6b-1'b)- $O$ - $\alpha$ L-glucopyranosyl-(6'b $\left.\rightarrow 1^{\prime \prime} b\right)$-glucopyranoside-17 $\alpha$ - $O$-Lglucopyranosyl-(6c $\left.\rightarrow 1^{\prime} c\right)-O$-L-glucopyranosyl-(6'c $\left.\rightarrow 1^{\prime \prime} c\right)-$ $O$-L-glucopyranoside-19 $\alpha$ - $O$-L-glycopyranosyl-(6d $\rightarrow 1$ 'd)$\boldsymbol{O}$ - $\alpha$-L-glucopyranosyl-(6'd $\rightarrow \mathbf{1}$ 'd)- $\boldsymbol{O}$ - $\boldsymbol{a}$-L-glucopyranoside (1): Colourless gum; $\mathrm{R}_{\mathrm{f}} 0.43\left(\mathrm{CHCl}_{3}: \mathrm{MeOH} ; 8: 2\right) ;[\alpha]_{\mathrm{D}}{ }^{23}+$ 34.2 (c, 1); ${ }^{1} \mathrm{H}\left(\mathrm{MeOD}, 600 \mathrm{MHz}\right.$ ) and ${ }^{13} \mathrm{C}$ NMR (MeOD, 150 MHz) (Table-1); IR (KBr, $\left.v_{\max }, \mathrm{cm}^{-1}\right)$ : 3490, 3365, 3285, 3215, 2950, 2847, 1702, 1690, 1465, 1360, 1210, 1059, 721; FAB MS (positive mode) $m / z 2537[\mathrm{M}+\mathrm{H}]^{+}\left(\mathrm{C}_{102} \mathrm{H}_{177} \mathrm{O}_{71}\right)(2.1)$, 505 (2.5), 342 (12.6), 180 (9.3), 163 (46.7).

\section{RESULTS AND DISCUSSION}

Compound 1, was obtained as a colourless gum from butanol extracts. It responded to glycosidic test positive and the IR spectrum showed characteristic absorption bands for hydroxyl groups $\left(3490,3365,3285 \mathrm{~cm}^{-1}\right)$ and carboxylic function $\left(3215,1702,1690 \mathrm{~cm}^{-1}\right)$. On the basis of FAB mass and ${ }^{13} \mathrm{C}$ NMR spectra the molecular ion peak was determined at $\mathrm{m} / z 2537[\mathrm{M}+\mathrm{H}]^{+}$corresponding to the molecular formula of an acyclic triterpenic dodecane glycoside $\mathrm{C}_{102} \mathrm{H}_{177} \mathrm{O}_{71}$. The ion peaks arising at $m / z 163\left[\mathrm{C}_{6} \mathrm{H}_{11} \mathrm{O}_{5}\right]^{+}, 180\left[\mathrm{C}_{6} \mathrm{H}_{12} \mathrm{O}_{6}\right]^{+}, 342$ $\left[\mathrm{C}_{12} \mathrm{H}_{22} \mathrm{O}_{11}\right]^{+}$and $505\left[\mathrm{C}_{6} \mathrm{H}_{11} \mathrm{O}_{5}-\mathrm{C}_{12} \mathrm{H}_{22} \mathrm{O}_{11}\right]^{+}$indicated the presence of hexose sugar units in the molecule.

${ }^{1} \mathrm{H}$ NMR spectrum of $\mathbf{1}$ showed twelve one-proton doublets from $\delta 5.31$ to 4.47 ( $J=6.0$ to $4.8 \mathrm{~Hz}$ ) assigned to $\alpha$-oriented 


\begin{tabular}{|c|c|c|}
\hline \multicolumn{3}{|c|}{$\begin{array}{c}\text { TABLE-1 } \\
{ }^{1} \mathrm{H} \text { AND }{ }^{13} \mathrm{C} \text { NMR SPECTRAL DATA OF COMPOUND } 1\end{array}$} \\
\hline Position & ${ }^{1} \mathrm{H}$ NMR & ${ }^{13} \mathrm{C}$ NMR \\
\hline 1 & $1.38 \mathrm{~d}(6.6)$ & 20.86 \\
\hline 2 & $2.12 \mathrm{~m}$ & 42.22 \\
\hline 3 & $3.80 \mathrm{dd}(3.0,6.0)$ & 72.38 \\
\hline 4 & 3.68 ddd $(3.6,6.0,8.4)$ & 72.20 \\
\hline 5 & $2.55 \mathrm{~m}, 2.43 \mathrm{~m}$ & 42.75 \\
\hline 6 & $2.59 \mathrm{~m}$ & 33.31 \\
\hline 7 & $2.61 \mathrm{~m}, 2.10 \mathrm{~m}$ & 32.89 \\
\hline 8 & $1.88 \mathrm{~m}$ & 38.44 \\
\hline 9 & $2.14 \mathrm{~m}, 1.85 \mathrm{~m}$ & 42.38 \\
\hline 10 & $2.45 \mathrm{~m}$ & 42.73 \\
\hline 11 & $2.16 \mathrm{~m}, 2.09 \mathrm{~m}$ & 21.26 \\
\hline 12 & $1.71 \mathrm{~m}, 1.81 \mathrm{~m}$ & 32.18 \\
\hline 13 & $1.80 \mathrm{~m}$ & 33.31 \\
\hline 14 & $1.73 \mathrm{~m}$ & 34.55 \\
\hline 15 & $1.60 \mathrm{~m}, 1.63 \mathrm{~m}$ & 25.79 \\
\hline 16 & $1.52 \mathrm{~m}$ & 41.24 \\
\hline 17 & 3.63 ddd $(5.4,3.6,2.4)$ & 71.78 \\
\hline 18 & $2.08 \mathrm{~m}$ & 32.88 \\
\hline 19 & 3.71 ddd $(6.0,3.6,2.4)$ & 71.41 \\
\hline 20 & $1.58 \mathrm{~m}$ & 45.57 \\
\hline 21 & $1.77 \mathrm{~m}, 1.83 \mathrm{~m}$ & 33.08 \\
\hline 22 & - & 79.05 \\
\hline 23 & $1.90 \mathrm{~m}, 1.82 \mathrm{~m}$ & 38.70 \\
\hline 24 & $1.20 \mathrm{t}(6.6)$ & 15.58 \\
\hline 25 & - & 179.82 \\
\hline 26 & - & 179.12 \\
\hline 27 & - & 178.30 \\
\hline 28 & $1.10 \mathrm{~d}(6.6)$ & 21.26 \\
\hline 29 & $0.65 \mathrm{~d}(6.0)$ & 10.92 \\
\hline 30 & 1.36 br s & 23.31 \\
\hline $1 \mathrm{a}$ & $5.03 \mathrm{~d}(5.4)$ & 107.06 \\
\hline $2 \mathrm{a}$ & $4.44 \mathrm{dd}(5.4,4.8)$ & 81.95 \\
\hline $3 a$ & $3.85 \mathrm{~m}$ & 65.12 \\
\hline $4 a$ & - & 88.71 \\
\hline $5 a$ & $4.50 \mathrm{~m}$ & 77.91 \\
\hline $6 a$ & 4.60 br s & 65.54 \\
\hline $1^{\prime} \mathrm{a}$ & $5.28 \mathrm{~d}(6.6)$ & 100.36 \\
\hline $2^{\prime} \mathrm{a}$ & $4.20 \mathrm{~m}$ & 76.60 \\
\hline $3 ' a$ & $3.87 \mathrm{~m}$ & 74.62 \\
\hline $4^{\prime} \mathrm{a}$ & $3.56 \mathrm{~m}$ & 73.12 \\
\hline $5^{\prime} \mathrm{a}$ & $4.53 \mathrm{~m}$ & 81.95 \\
\hline 6'a & $4.30 \mathrm{br} \mathrm{s}$ & 62.645 \\
\hline $1 " \mathrm{a}$ & $5.31 \mathrm{~d}(6.2)$ & 100.23 \\
\hline $2 " \mathrm{a}$ & $4.05 \mathrm{~m}$ & 76.48 \\
\hline 3"a & $3.82 \mathrm{~m}$ & 74.34 \\
\hline $4 " \mathrm{a}$ & $3.57 \mathrm{~m}$ & 72.50 \\
\hline $5 " \mathrm{a}$ & $4.38 \mathrm{~m}$ & 77.91 \\
\hline $6 " \mathrm{a}$ & $3.30 \mathrm{~d}(6.6), 3.32 \mathrm{~d}(6.6)$ & 61.81 \\
\hline $1 b$ & $4.98 \mathrm{~d}(6.6)$ & 106.76 \\
\hline $2 b$ & $4.63(6.6,3.6)$ & 82.43 \\
\hline $3 b$ & $3.95 \mathrm{~m}$ & 74.22 \\
\hline $4 b$ & - & 87.55 \\
\hline $5 b$ & $4.47 \mathrm{~m}$ & 79.72 \\
\hline $6 b$ & $3.56 \mathrm{~d}(9.0), 3.54 \mathrm{~d}(9.0)$ & 60.85 \\
\hline $1 ' b$ & $5.17 \mathrm{~d}(3.6)$ & 100.99 \\
\hline $2^{\prime} \mathrm{b}$ & $4.97 \mathrm{~m}$ & 76.31 \\
\hline 3'b & $3.79 \mathrm{~m}$ & 74.72 \\
\hline $4^{\prime} \mathrm{b}$ & $3.50 \mathrm{~m}$ & 72.80 \\
\hline $5 ' b$ & $4.46 \mathrm{~m}$ & 78.22 \\
\hline 6'b & $3.54 \mathrm{~d}(4.0), 3.52 \mathrm{~d}(9.0)$ & 63.58 \\
\hline $1 " b$ & $5.07 \mathrm{~d}(6.1)$ & 94.10 \\
\hline $2 " b$ & 4.01 & 75.83 \\
\hline 3"b & $3.89 \mathrm{~m}$ & 73.99 \\
\hline
\end{tabular}

\begin{tabular}{|c|c|c|}
\hline $4 " \mathrm{~b}$ & $3.49 \mathrm{~m}$ & 72.07 \\
\hline $5 " \mathrm{~b}$ & $4.45 \mathrm{~m}$ & 78.03 \\
\hline $6 " \mathrm{~b}$ & 3.34 br s & 61.06 \\
\hline $1 \mathrm{c}$ & $5.09 \mathrm{~d}(5.8)$ & 104.23 \\
\hline $2 \mathrm{c}$ & $4.12 \mathrm{~m}$ & 75.52 \\
\hline $3 c$ & $3.65 \mathrm{~m}$ & 69.13 \\
\hline $4 c$ & 3.46 & 66.88 \\
\hline $5 c$ & $4.47 \mathrm{~m}$ & 81.78 \\
\hline $6 c$ & $3.70 \mathrm{~d}(8.4), 3.68(8.4)$ & 60.62 \\
\hline $1^{\prime} \mathrm{c}$ & $4.87 \mathrm{~d}(6.7)$ & 93.69 \\
\hline $2^{\prime} \mathrm{c}$ & $4.10 \mathrm{~m}$ & 75.52 \\
\hline $3 ' \mathrm{c}$ & $3.71 \mathrm{~m}$ & 67.33 \\
\hline $4^{\prime} \mathrm{c}$ & $3.49 \mathrm{~m}$ & 68.40 \\
\hline $5 ' \mathrm{c}$ & $4.64 \mathrm{~m}$ & 79.22 \\
\hline $6 ' \mathrm{c}$ & $3.60 \mathrm{~d}(6.6), 3.58 \mathrm{~d}(6.6)$ & 63.62 \\
\hline $1 " \mathrm{c}$ & $4.77 \mathrm{~d}(5.1)$ & 95.06 \\
\hline $2 " \mathrm{c}$ & $4.03 \mathrm{~m}$ & 75.38 \\
\hline $3 " \mathrm{c}$ & $3.66 \mathrm{~m}$ & 68.69 \\
\hline $4 " \mathrm{c}$ & $3.50 \mathrm{~m}$ & 79.05 \\
\hline $5 " \mathrm{c}$ & $4.27 \mathrm{~m}$ & 79.05 \\
\hline 6"c & 3.28 br s & 61.81 \\
\hline $1 d$ & $4.65 \mathrm{~d}(3.6)$ & 104.03 \\
\hline $2 d$ & $4.13 \mathrm{~m}$ & 75.21 \\
\hline $3 d$ & $3.66 \mathrm{~m}$ & 68.18 \\
\hline $4 d$ & $3.52 \mathrm{~m}$ & 65.43 \\
\hline $5 d$ & $4.26 \mathrm{~m}$ & 78.68 \\
\hline $6 d$ & $3.68 \mathrm{~d}(8.4), 3.66 \mathrm{~d}(8.4)$ & 61.39 \\
\hline 1 'd & $4.76 \mathrm{~d}(6.3)$ & 94.01 \\
\hline $2^{\prime} d$ & $3.97 \mathrm{~m}$ & 75.11 \\
\hline $3 ' d$ & $3.78 \mathrm{~m}$ & 73.57 \\
\hline $4^{\prime} d$ & $3.50 \mathrm{~m}$ & 65.31 \\
\hline $5 ' d$ & $4.38 \mathrm{~m}$ & 79.05 \\
\hline $6 ' d$ & $3.50 \mathrm{~d}(9.0), 3.48 \mathrm{~d}(9.0)$ & 63.72 \\
\hline $1 " \mathrm{~d}$ & $4.07 \mathrm{~d}(4.8)$ & 98.35 \\
\hline $2 " d$ & $3.98 \mathrm{~m}$ & 74.86 \\
\hline $3 " \mathrm{~d}$ & $3.77 \mathrm{~m}$ & 73.12 \\
\hline $4 " d$ & $3.49 \mathrm{~m}$ & 65.48 \\
\hline $5 " d$ & $4.30 \mathrm{~m}$ & 78.80 \\
\hline $6 " \mathrm{~d}$ & 3.34 br s & 61.39 \\
\hline
\end{tabular}

anomeric protons. The other sugar protons appeared between $\delta 4.60$ - 3.34. A one proton doublet doublet at $\delta 3.80(J=3.0$, $6.0 \mathrm{~Hz})$ and three one proton doublets at $\delta 3.68(J=3.6,6.0$, $8.4 \mathrm{~Hz}), 3.63(J=5.4,3.6,2.4)$ and $\delta 3.71(J=6.0,3.6,2.4)$ were ascribed $\beta$-oriented oxygenated methine $\mathrm{H}-3 \beta, \mathrm{H}-4 \beta$, $\mathrm{H}-17 \beta$ and $\mathrm{H}-19 \beta$ protons, respectively. The appearance of oxygenated methylene protons of the sugar units in the deshielded region at $\delta 4.60\left(\mathrm{H}_{2}-6 \mathrm{a}\right), 4.30\left(\mathrm{H}_{2}-6^{\prime} \mathrm{a}\right), 3.56,3.54$ $\left(\mathrm{H}_{2}-6 \mathrm{~b}\right), 3.54,3.52\left(\mathrm{H}_{2}-6^{\prime} \mathrm{b}\right), 3.70,3.68\left(\mathrm{H}_{2}-6 \mathrm{c}\right), 3.60,3.58\left(\mathrm{H}_{2^{-}}\right.$ $\left.6{ }^{\prime} \mathrm{c}\right), 3.68,3.66\left(\mathrm{H}_{2}-6 \mathrm{~d}\right)$ and $3.50,3.48\left(\mathrm{H}_{2}-6^{\prime} \mathrm{d}\right)$ suggested $(6 \rightarrow 1)$ linkages of the sugar chain. A broad signal at $\delta 1.36$, a triplet at $\delta 1.20(J=6.6)$ and three doublets at $\delta 1.38(J=6.6$ $\mathrm{Hz}), 1.10(J=6.6 \mathrm{~Hz})$ and $0.65(J=6.0 \mathrm{~Hz})$, all integrating for three-protons each, were attributed to tertiary $\mathrm{C}-30$, primary C-24 and secondary C-1, C-28 and C-29 methyl protons, respectively. The remaining methine and methylene protons appeared from $\delta 2.61$ to 1.52 . The ${ }^{13} \mathrm{C}$ NMR spectrum of $\mathbf{1}$ exhibited signals for carboxylic carbons at $\delta 179.82$ (C-25), 179.12 (C-26), 178.30 (C-27), quaternary hydroxy substituted carbon at $\delta 79.05(\mathrm{C}-22)$, oxygenated methine carbons at $\delta$ 72.38 (C-3), 72.20 (C-4), 71.78 (C-17) and $\delta 71.41$ (C-19), anomeric and other sugar carbons from $\delta 107.06$ to 60.97 and methyl carbons at $\delta 20.86$ (C-1), 15.58 (C-2a), 21.26 (C-28), 
$10.92(\mathrm{C}-29)$ and $\delta 22.31$ (C-30). The presence of the two sugar carbons in the deshielded region at $\delta 107.06(\mathrm{C}-1 \mathrm{a})$, $81.95(\mathrm{C}-2 \mathrm{a}), 88.71(\mathrm{C}-4 \mathrm{a})$ and $\delta 106.76(\mathrm{C}-1 \mathrm{~b}), 82.43(\mathrm{C}-2 \mathrm{~b})$ and $87.55(\mathrm{C}-4 \mathrm{~b})$, indicated furanic forms of these sugar units. The interactions of the anomeric C-1a with $\mathrm{H}-3, \mathrm{H}-2$ and $\mathrm{H} 2-4$; and $\mathrm{C}-1 \mathrm{~b}$ with $\mathrm{H}-5$ and $\mathrm{H}_{2}-4$ in the $\mathrm{HMBC}$ spectrum suggested the attachment of furanic sugars to the triterpenic chain. The interactions of C-25 with Me-1, H-2 and H-3; C-26 with H-6, $\mathrm{H}-5$ and $\mathrm{H}_{2}-7$; and $\mathrm{C}-27$ with $\mathrm{H}-10, \mathrm{H}_{2}-9$ and $\mathrm{H}_{2}-11$ in the $\mathrm{HMBC}$ spectrum supported linkages of the carboxylic functions to triterpene. The correlations of $\mathrm{C}-22$ with $\mathrm{H}_{2}-21, \mathrm{H}_{2}-23$ and $\mathrm{Me}-24$ and Me-30 in the HMBC spectrum indicated the existence of one of the oxygenated carbon near the primary carbon. The attachment of the sugar units with the triterpenic unit was supported by the ${ }^{1} \mathrm{H}-{ }^{1} \mathrm{H}$ COSY spectrum. The correlations of the oxygenated methine, sugar and methyl carbons with the respective protons were deduced from the HSQC spectrum. On the basis of these evidences the structure of $\mathbf{1}$ was established as 14,18,22-trimethyl $3 \alpha, 5 \alpha, 17 \alpha, 19 \alpha, 22 \alpha$ pentahydroxytetracosan-25,26,27-trioic acid-3 $\alpha-O-\alpha$-Lglucofuranosyl-(6a $\rightarrow 1$ 'a)- $O$ - $\alpha$-L-glucopyranosyl-(6'a $\rightarrow 1$ "a)$O$ - $\alpha$-L-glucopyranoside- $5 \alpha-O$ - $\alpha$-L-glucofuranosyl- $(6 \mathrm{~b} \rightarrow 1$ 'b)$O$ - $\alpha$-L-glucopyranosyl-(6'b $\rightarrow 1$ "b)-glucopyranoside- $17 \alpha-O$-Lglucopyranosyl-(6c $\rightarrow 1$ 'c)- $O$-L-glucopyranosyl-(6'c $\rightarrow 1$ "c)-OL-glucopyranoside- $19 \alpha-O$-L-glycopyranosyl- $(6 \mathrm{~d} \rightarrow 1$ 'd)- $O$ - $\alpha$ L-glucopyranosyl-(6'd $\rightarrow 1$ "d)- $O$ - $a$-L-glucopyranoside. This is new acyclic triterpenic glycoside.

\section{ACKNOWLEDGEMENTS}

The authors acknowledge the continuous support of research center, College of Pharmacy and Deanship of Scientific Research in King Saud University, Riyadh, KSA.

\section{REFERENCES}

1. Y. Peng, C. Ma, Y. Li, K.S.Y. Leung, Z.H. Jiang and Z. Zhao, Plant Foods Hum. Nutr., 60, 161 (2005).

2. Pharmacopoeia of the People's Republic of China, Chemical Industry Press, Beijing (2000).

3. O. Potterat, Planta Med., 76, 7 (2010).

4. S. Funayama, K. Yoshida, C. Konno and H. Hikino, Tetrahedron Lett., 21, 1355 (1980).

5. J. Yamahara, M. Kim, T. Sawada and H. Fujimua, Shoyakugaku Zasshi, 18, 33 (1964).

6. S.Y. Kim, Y.H. Choi, H. Huh, J. Kim, Y.C. Kim and H.S. Lee, J. Nat. Prod., 60, 274 (1997).

7. M. Noguchi, K. Mochida, T. Shingu, M. Kozuka and K. Fujitani, Chem. Pharm. Bull. (Tokyo), 32, 3584 (1984).

8. K. Jung, Y.W. Chin, Y.C. Kim and J. Kim, Arch. Pharm. Res., 28, 1381 (2005).

9. Y.G. Shin, K.H. Cho, J.M. Kim, M.K. Park and J.H. Park, J. Chromatomatogr. A, 857, 331 (1999).

10. D.G. Lee, H.J. Jung and E.R. Woo, Arch. Pharm. Res., 28, 1031 (2005).

11. N. Asano, A. Kato, M. Miyauchi, H. Kizu, T. Tomimori, K. Matsui, R.J. Nash and R.J. Molyneux, Eur. J. Biochem., 248, 296 (1997).

12. Z. Zhang, X. Liu, T. Wu, J. Liu, X. Zhang, X. Yang, M.J. Goodheart, J.F. Engelhardt and Y. Wang, Cell Biol. Toxicol., 27, 107 (2011).

13. C.C. Wang, S.C. Chang, B.S. Inbaraj and B.H. Chen, Food Chem., 120, 184 (2010).

14. Y.W. Chin, S.W. Lim, S.H. Kim, D.Y. Shin, Y.G. Suh, Y.B. Kim, Y.C. Kim and J. Kim, Bioorg. Med. Chem. Lett., 13, 79 (2003).

15. S. Yahara, C. Shigeyama, T. Ura, K. Wakamatsu, T. Yasuhara and T. Nohara, Chem. Pharm. Bull. (Tokyo), 41, 703 (1983).

16. X.M. Peng and G.Y. Tian, Carbohydr. Res., 331, 95 (2001).

17. G.-Q. Zheng, Z.-Y. Zheng, X. Xu and Z.-H. Hu, Biochem. Syst. Ecol., 38, 275 (2010).

18. X.M. Li, X.L. Li and A.G. Zhou, Eur. Polym. J., 43, 488 (2007).

19. M. Ming, L. Guanhua, Y. Zhanhai, C. Guang and Z. Xuan, Food Chem., 113, 872 (2009).

20. W.-S. Jung, I.-M. Chung, M. Ali and A. Ahmad, J. Asian Nat. Prod. Res., 14, 301 (2012).

21. I.-M. Chung, M. Ali, E.-H. Kim and A. Ahmad, J. Asian Nat. Prod. Res., 15, 136 (2013).

22. X.-N. Li, C. Chu, S.-Q. Tong, D.-P. Cheng and J.-Z. Yan, Nat. Prod. Res., 27, 750 (2013). 